\title{
Use of Analogy by Public Health Nurses in Problem Solving for Individual Consultations in Japan: A Multiple Case Study
}

\author{
Masako Kageyama ${ }^{*}$, Taeko Shimazu2 ${ }^{2}$ Atsuko Taguchi' ${ }^{3}$, Satoko Nagata4, Kathy Magilvy5 \\ ${ }^{1}$ Area of Integrated Health and Nursing Science, Osaka University Graduate School of Medicine, Suita, Japan \\ ${ }^{2}$ National College of Nursing, Kiyose, Japan \\ ${ }^{3}$ Department of Public Health Nursing, Division of Health Sciences, Tohoku University Graduate School of Medicine, \\ Sendai, Japan \\ ${ }^{4}$ Department of Community Health Nursing, Graduate School of Medicine, The University of Tokyo, Tokyo, Japan \\ ${ }^{5}$ University of Colorado College of Nursing, Denver, USA \\ Email: *kageyama@sahs.med.osaka-u.ac.jp
}

How to cite this paper: Kageyama, M., Shimazu, T., Taguchi, A., Nagata, S. and Magilvy, K. (2017) Use of Analogy by Public Health Nurses in Problem Solving for Individual Consultations in Japan: A Multiple Case Study. Open Journal of Nursing, 7, 345-360

https://doi.org/10.4236/ojn.2017.73028

Received: February 8, 2017

Accepted: March 17, 2017

Published: March 20, 2017

Copyright (c) 2017 by authors and Scientific Research Publishing Inc. This work is licensed under the Creative Commons Attribution International License (CC BY 4.0).

http://creativecommons.org/licenses/by/4.0/

\begin{abstract}
Aim: Nurses must develop good problem-solving skills (PSS) to work in the complex health care environment. This study explored PHNs' use of analogy in PSS development. The purposes of the study were to clarify how PSS developed in one area (i.e., mental health) could be applied to another area (i.e., maternal health) and whether new PSS could develop in response to PSS gained in another area. Methods: A multiple case study was conducted using interviews. We interviewed 27 consultations from eight Japanese PHNs who consulted in mental health departments before transferring to maternal health departments. The data on how PHNs applied PSS in the selection, mapping, evaluation, and learning stages of the analogy process were extracted from transcribed interviewed data and compared. Results: PHNs provided 59 PSS used in 27 consultations. All PHNs applied past mental health PSS to solve new problems in maternal health. They tended to select past PSS based on structural similarity and to apply PSS via low-level abstraction in serious situations or preventively to avoid causing the current situation to worsen. Notably, PHNs developed maternal health PSS by using past mental health PSS; these new PSS were derived through analogy from various failures and successes. Conclusions: PSS developed in one area can be applied in another area, and new PSS can develop through applying these previous PSS. Identification of structural similarities and preventive analogies must be included in nursing education, especially for nurses working in public health fields.
\end{abstract}

\section{Keywords}

Analogy, Consultation, Nursing Education, Problem Solving, Public Health Nurse 


\section{Introduction}

Current rapid social change and the highly complex health care environment indicate a need for nurses to develop good problem-solving skills (PSS) in complex situations [1]. In Japan, the complexity of many health issues and policies has led to a rise in specialized service departments, leading to new health-related demands for public health nurses (PHN) working in the community. Increasingly, more PHNs are obtaining work opportunities in unfamiliar areas of practice, meaning that they must also solve unfamiliar problems. PHNs-and indeed all nurses working in the community-must develop high-level PSS to deal with these unfamiliar problems. These skills need to be incorporated into nursing education and practiced to produce students with flexibility and competence in problem-solving.

PSS are essential skills for nurses along with critical thinking [2]. Notably, "problem-solving" and "critical thinking" are often used interchangeably [2] [3]. Both are the focus of problem-based learning (PBL), a prominent student-centered approach in nursing education [4] [5]. In the present study, we focus on PSS using analogy, which may be an important means of solving particularly unfamiliar problems [6]. Analogy in problem solving refers to how people recognize similarities between a familiar problem (i.e., the base) and a relatively unfamiliar problem (i.e., the target), and apply the solution of the base to the target [7] [8]. Analogy has been examined in a variety of fields and is recognized as a key concept of relational reasoning, which holds an increasingly important place in educational practice [9].

PHNs must expend considerable time and effort to learn new PSS upon transferring departments. However, this does not necessarily mean that transferring requires PHNs to start from the beginning; indeed, PHNs can generally apply PSS acquired in previous departments. However, it has not been empirically demonstrated how PHNs apply such past PSS to new areas of practice, and whether PSS in the new areas can be developed using those learned in past areas. Identifying the characteristics of PSS using analogy in PHNs would help inform and improve nursing education strategies including PBL.

We apply the framework for analogy in this study to clarify how PHNs apply PSS from a particular area to new areas. In this study, we select the areas of mental and maternal health because of their inherent relationship: for instance, there is strong evidence that parents with mental health issues are more likely to abuse their children [10]. In Japan, the main areas of public health practice in which consultations are provided are as follows: maternal health, adult health, geriatric health, mental health, communicable diseases, intractable diseases, and handicapped persons. Recently, a new area in which consultations are provided-persons under social assistance-has emerged. Maternal health is the largest area for PHNs [11]. All of these areas are addressed by local government departments, with some governments having specific departments for each area and others having several areas covered by a single department. 


\subsection{Research Questions}

We sought to answer two research questions. In a public health setting, how can mental health PSS be applied to maternal health PSS? Can maternal health PSS be developed using mental health PSS?

\subsection{Analogy}

According to Holyoak \& Thagard [12], analogy in problem-solving comprises the following process: a problem-solver selects a base by retrieving information about it from memory (selection), after which they "map" the base to the target and generate inferences about that target (mapping); then, they adapt and evaluate these inferences to consider the unique aspects of the target (evaluation), and eventually learn something more general from the success or failure of the analogy (learning).

As noted in the above process, analogical thinking must begin with retrieval of an appropriate base from the massive storage of long-term memory [13]. Holyoak and Koh [14] posited that bases and targets possess two levels of similarity: surface and structural. Surface similarity refers to a resemblance between the objects in the base and target and their properties, whereas structural similarity is a resemblance between the underlying systems of relations in the base and target [15]. Generally, surface similarity is the main determinant of base access and facilitates retrieval [16], while structural similarity influences mapping and is considered the defining feature of analogy [17].

Base knowledge arises from both particular case(s) and abstract knowledge consolidated from many cases [18], [19]. Resolving ambiguous mappings in an analogy is done by employing the type of relation most relevant to the person's goal [12].

\section{Methods}

\subsection{Design and Sample}

This study employed the multiple case study design mentioned by Yin [20]. This type of case study inquiry benefits from prior development of theoretical propositions to guide data collection and analysis. The case unit of this study comprised three levels: the first level was the PHN, the second level the consultation, and the third level the PSS. The PSS were considered the main case unit because our aim was to study their applications via analogy. A case study format allowed us to use a combination of qualitative and quantitative data [20]. This study used the analogy process explicated by Holyoak \& Thagard [12] as the framework.

We employed objective sampling in order to obtain PHNs who had specifically used analogy in problem-solving. Specifically, based on prior research related to analogy, we needed PHNs who had experience working in two different departments. Using analogy depends on temporal continuity [21] for accurate recall; therefore, the inclusion criteria were being a PHN who had transferred from a mental health department to a maternal health department within the past five 
years (because this would ensure that their memories of the former department were fresh) and who was still working in the maternal health department (to prevent contamination of memories). We included PHNs who had initially worked in the maternal health department as well as PHNs who had worked in maternal health department before working in mental health department, because we were also interested in whether maternal health PSS can be developed using mental health PSS.

\subsection{Data Collection}

In the Kanto area of Japan, 12 cities had both mental health and maternal health departments in their public health system. We contacted these 12 cities in January 2014 to identify currently working PHNs who met the inclusion criteria. Of these 12 cities, seven had PHNs who met the inclusion criteria. We sent research announcement documents to one or two potential candidates in each city; if the candidates were interested, they were contacted by the first author. One candidate declined participation because she could not talk about her consultations. Thus, eight PHNs working in six cities participated in the study.

A total of 8 participants in the sample had an average age of 42.9 (range 35 52) and all were female. Their average years of experiences as PHNs were 18.5 (range 11 - 27) and they transferred to the maternal health department within 1 4 years after the mental health department. Before transferring to their current maternal health department, five PHNs had previous experience working in maternal health departments and three PHNs did not.

We asked PHNs to talk about three or four consultations that they themselves had judged to involve application of mental health PSS to maternal health PSS. A consultation in terms of public health interventions is defined as the process of seeking "information and [generating] optional solutions to perceived problems or issues through interactive problem-solving with a community, system, family or individual" [22].

The interviews were semi-structured, lasted for 90 - 120 minutes, and used an interview guide that followed the analogy process. The interview guide was pretested by two PHNs. They found that they could not speak in detail about their consultations because of how complex and long the consultations were, so the guide was modified to facilitate easier conversation. The guide consisted of the following: (1) a summary of situations involving a maternal health consultation (target) and a mental health consultation (base); (2) the similarities between the target and base, how they were connected, and whether participants had had previous similar consultations (selection); (3) how participants applied the base PSS to the target PSS (mapping); (4) whether the analogy was a success or a failure and why (evaluation); and (5) what participants learned from the analogy (learning). We asked PHNs about points (2) to (5) for each PSS used in a consultation. The structure of the analogy process in this study is shown in Figure 1. 


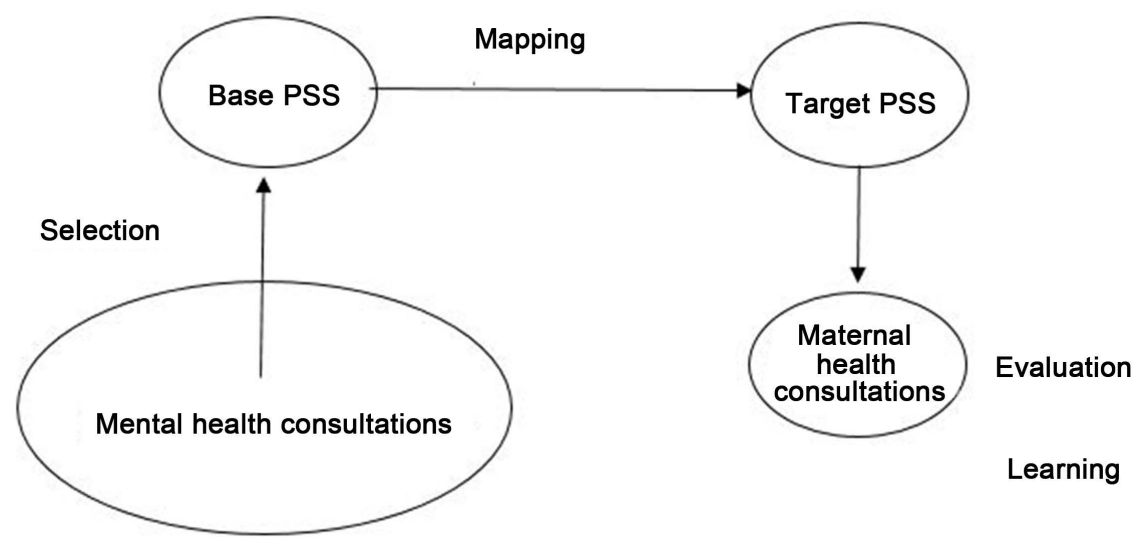

Figure 1. Structure of the analogy process in this study.

\subsection{Analytic Strategy}

The interviews were recorded and transcribed with the permission of the participants. The first author analyzed all of the data. The analysis of the first level of the case unit involved describing the demographic characteristics of the PHNs. Next, we confirmed the number and types of consultations as the analysis of the second level. Finally, regarding the analysis of the third level, PSS were identified and organized as follows: PSS as a target, PSS as a base, surface similarity, structural similarity, and decisive similarity in selection of the base, the presence of particular consultations as a base, mapping, evaluation, and learning. In the selection stage, surface similarity was considered to be a history of psychiatric treatment, which is an objective index of mental illness. Decisive similarity refers to PHNs' relatively intuitive judgments about the strongest surface or structural similarities between the base and target. Regarding the mapping stage, in analogy research, higher levels of abstraction enable more crucial and better applications of the analogy [23]. Therefore, in the mapping stage, we distinguished analogy in terms of high and low levels of abstraction in similarities between the base and target. A low level of abstraction indicates that the similarity of the base and target PSS is obvious, while a high level indicates that the similarity is not obvious. Because we found some shared aspects in surface and structural similarities in the selection stage and mapping patterns in the mapping stage, we created sub-items for each of these categories.

\subsection{Quality Assurance of Results}

Regarding construct validity, we asked interviewees to confirm case information by viewing their consultation reports. Case studies aim to expand and generalize theories (analytic generalization) rather than enumerate frequencies (statistical generalization) [20]. The sample size was enough to ensure that case findings overlapped, allowing better analytic generalization. One of the co-authors assisted with the discussion of findings by reviewing data and qualitative analysis. Regarding the reliability, two co-authors analyzed the same cases independently for two consultations. They read the transcribed data, identified the target and base PSS, and conducted the same analysis as the first author. After this analysis, they 
compared their results with each other and with those of the first author. In addition, all participants were asked for member checks and all agreed with the main results of this study.

\subsection{Ethical Considerations}

The summary and objectives of this study, voluntary basis of participation, confidentiality, and autonomy were explained to PHNs orally and in writing. Written consent was obtained before each interview. This study was approved by the Research Ethics Committee, the Faculty of Medicine, the University of Tokyo (January 8, 2014; No. 10358).

\section{Results}

The analysis flow and main results are shown in Figure 2. Of the 8 PHNs (i.e., the first level of the case unit), five PHNs had previous experience working in maternal health departments before transferring to their current maternal health department, and three PHNs did not. Regarding the second level of the case unit, twenty-seven maternal health consultations were reported by the eight PHNs,

First level of case unit (PHN)

I- 8 PHNs

Second level of case unit (consultation)

- 27 maternal health consultations ( 24 for child abuse and 3 for childcare and child education)

Third level of case unit (PSS)

- 59 PSS

1. Selection stage

- Surface similarity

A history of psychiatry treatment (13 consultations, 28 PSS) and paychiatric symptoms ( 15 consultations, 38 PSS)

- Structural similarity

Client reactions (14 PSS), client condition or situation (35 PSS), and methods of support (13 PSS)

- Decisive similarity

A history of psychiatry treatment (2 PSS), psychiatric symptoms (10 PSS), client reactions (11 PSS), client condition or situation (26 PSS), and methods of support (10 PSS)

- Particular consultations

Presence (13 PSS)

2. Mapping stage

- Level of abstraction in similarity High (7 PSS) and low (52 PSS)

- Signature patterns Preventive mapping (20 PSS), adjusted mapping from failure (11 PSS), and attitude mapping while supporting (3 PSS)

3. Evaluation stage

- Failures or difficult to accurately judge (5 PSS)

4. Learning stage

- Learning experience

Figure 2. Flow of analysis and main results. PSS: problem-solving skill; PHN: public health nurse. 
24 for child abuse prevention and three for childcare and child education. Finally, regarding the third level of the case unit, PHNs used 1 - 4 PSS with analogies per consultation. A total of 59 PSS with analogies were included as main case units for further analysis. We explained how PHNs applied the mental health PSS to maternal health PSS at each stage of the analogy process.

\subsection{Selection Stage}

The selection stage refers to how a PHN selects a PSS as a base by retrieving information about it from memory to solve a target current problem. We sought to understand how PHNs selected the base in terms of surface, structural, and decisive similarity, as well as the presence of particular consultations as a base.

Regarding surface similarity, we added a sub-item of psychiatric symptoms as an objective index of mental illness. A history of psychiatric treatment appeared in 13 consultations (28 PSS) and psychiatric symptoms in 15 consultations (38 PSS).

Regarding structural similarity, we created sub-items of "client reactions", "client condition or situation" and "methods of support by PHNs". Client reactions included 14 PSS and consisted of client verbal responses, facial expressions, and attitude to PHNs. Client condition or situation included 35 PSS and consisted of strange smells, clumsy, mother transferring from another area, a period of instability, self-accusation, and difficult childhood. The methods of support by PHNs included 13 PSS and consisted of step-by-step approaches, making changes to the current situation, and finding key people.

The decisive similarity in the base selection was a history of psychiatric treatment, with 2 of 27 PSS (7.4\%); psychiatric symptoms, with 10 of 38 PSS (26.3\%); client reactions, with 11 of 14 PSS (78.6\%); client condition or situation, with 26 of 37 PSS (70.3\%); and methods of support by PHNs, with 10 of 14 PSS (71.4\%). We noted that structural similarities were likely to be decisive for selecting bases. Exemplars of structural similarity are shown in Table 1.

Regarding particular consultations as a base, only thirteen PSS had them, while 37 PSS had abstract knowledge acquired from many consultations. Of the particular consultations used as a base, some had not directly involved the PHNs, who had heard the information from others. For example, one PHN stated:

A mother was hospitalized with postnatal depression. I heard that she was highly impulsive. In the previous mental health department, I heard of a child whose arms were impulsively cut by the mother. I also heard that a criminal with mental disorders killed her own child. Although they were not my clients, I judged that the mother would be high risk if she was discharged (No. 40).

\subsection{Mapping Stage}

The mapping stage refers to how PHNs map the base to the target and generate inferences about that target. Analogies were distinguished by high and low levels of abstraction in similarities between bases and targets in the mapping stage. High-level abstraction was found in seven PSS, five by PHNs who had not worked in a maternal health department previously and two by PHNs who had. High-level 
Table 1. Exemplars of structural similarity.

The mother was treated for schizophrenia ten years ago but was not
being treated by a psychiatrist at the time I saw her. She said, "I am cured."
The words hung over my head. I had many clients who said that in the
mental health department. They did not take medicine, against medical
advice, showed worse symptoms, and caused neighborhood trouble.
I often took such clients to the psychiatric hospital (No. 14)
Somebody with mental illness who moved from a rural region and
was unfamiliar with the area. The person was isolated and rock-faced,
lacked confidence in himself, and did not issue SOS signals by himself.
My first impression of the mother was similar to that for this person
because she was also rock-faced and lacked confidence in childrearing.
If I told her to consult me anytime, she would not consult herself.
So, I tried approaching her without waiting for contact from her.
Thitition support was similar to mental health PSS (No. 13)
The mother caused problems, like not picking her child from nursery
school or slapped the child. The nursery school discussed whether
they would give notice of child abuse to the child guidance center.
They decided not to give notice. In the mental health department,
I regretted not giving a warning against a violent client. This resulted
in serious injury to a family member. If I did warn against the client,
maybe the family member would not be seriously injured. Therefore,
I negotiated with the nursery school to give a notice of child abuse
so that the mother could learn what she should not do (No. 10)

abstraction was used when PHNs could not find solutions. They generated ideas for analogy and tested these ideas. In contrast, low-level abstraction was found in 52 PSS. Exemplars are shown in Table 2.

We found patterns of mapping specific to PHNs (signature patterns) in addition to standard patterns. The signature mapping patterns found were "preventive mapping," "adjusted mapping from failure," and "attitude mapping while supporting." Preventive mapping was found in 20 PSS (33.8\% of 59), and involved inferring about future changes from the client's background (client situation and condition), thereby preventing health conditions, childrearing behavior, and living conditions from worsening. Adjusted mapping from failure was found in 11 PSS, nine of which overlapped with preventive mapping. This mapping pattern referred to a base PSS being judged as a failure by the PHN; then, through reflecting on this failure, the PHN adjusted the PSS. Adjusted PSS were often aimed at preventing future failures in a given situation or condition. Attitude mapping when supporting was found in three cases. This mapping pattern referred to a base PSS mapping onto a target that was not a concrete skill but rather an attitude. Exemplars are shown on Table 3.

\subsection{Evaluation and Learning Stages}

The evaluation stage refers to how a PHN evaluates whether the application of the base PSS to the target PSS was successful. After evaluation comes, the learning stage, wherein, the PHN learns something more general from the success or failure of the analogy. In the evaluation and learning stages, many PSS were judged as 
Table 2. Exemplars of standard mapping.

\begin{tabular}{|c|c|}
\hline \multicolumn{2}{|r|}{ Mapping with high-level abstraction in similarity } \\
\hline Target & Understanding the true feelings of a mother with an autistic child \\
\hline Base & $\begin{array}{l}\text { Asking about early development history to understand the current } \\
\text { situation of a client with a mental disorder }\end{array}$ \\
\hline Similarity & A client's history reveals information about current situation and feelings \\
\hline Mapping & $\begin{array}{l}\text { Interview about mother's early development history to } \\
\text { understand her true feelings of having an autistic child }\end{array}$ \\
\hline $\begin{array}{l}\text { Story } \\
\text { interviewed }\end{array}$ & $\begin{array}{l}\text { I was worried about understanding the mother's true feelings. I came up } \\
\text { with an idea to do as a trial, which was interviewing her about her early } \\
\text { development history. I was taught by senior PHNs that interviewing about } \\
\text { this history is important because current situations are linked to past events. } \\
\text { We usually do not take an early development history in the maternal health } \\
\text { department but I interviewed the mother because I did not understand her } \\
\text { current feelings. After that, I felt closer to her and could understand her } \\
\text { feelings. She changed her attitude and opened up about her child (No. 56) }\end{array}$ \\
\hline \multicolumn{2}{|r|}{ Mapping with low-level abstraction in similarity } \\
\hline Target & $\begin{array}{l}\text { Help staff involved obtain a greater understanding } \\
\text { of a mother with intellectual disability }\end{array}$ \\
\hline Base & $\begin{array}{l}\text { Improving staff s understanding of a client with } \\
\text { mental disorders through interaction }\end{array}$ \\
\hline Similarity & Improving staffs understanding of a client through interaction \\
\hline Mapping & $\begin{array}{l}\text { Through interaction with the mother with intellectual disability, } \\
\text { staff involved will better understand such clients }\end{array}$ \\
\hline $\begin{array}{l}\text { Story } \\
\text { interviewed }\end{array}$ & $\begin{array}{l}\text { It is important to watch persons with disorders in the community. Especially } \\
\text { persons with mental disorders, who tend not to put messages out. In the } \\
\text { mental health department, I went to the local government office with persons } \\
\text { with mental disorders and helped staff involved to understand them. So I } \\
\text { created opportunities for the mother to meet with staff involved and expected } \\
\text { those involved to learn something by making a connection with us (No. 34) }\end{array}$ \\
\hline
\end{tabular}

Table 3. Exemplars of signature mapping for PHNs.

\begin{tabular}{|c|c|}
\hline \multicolumn{2}{|r|}{ Preventive mapping } \\
\hline Target & Pregnant woman with bipolar disorder \\
\hline Base & $\begin{array}{l}\text { Introduction of home help service soon after birth for a mother } \\
\text { with a mental disorder who could not take care of her baby }\end{array}$ \\
\hline Mapping & $\begin{array}{l}\text { Preparing to introduce childcare services during } \\
\text { pregnancy to prevent poor childrearing practices }\end{array}$ \\
\hline $\begin{array}{l}\text { Story } \\
\text { interviewed }\end{array}$ & $\begin{array}{l}\text { I took a call from a relevant agency about a pregnant woman with bipolar } \\
\text { disorder. In the mental health department, a client with a mental disorder } \\
\text { gave birth. However, the client could not take care of the baby, so I hastily } \\
\text { contacted childcare services. Therefore, I predicted that the mother would } \\
\text { find it difficult to take care of her baby. In the postnatal period, even a } \\
\text { healthy mother will find it difficult with perverse baby and } \\
\text { hormone imbalance. [...] So I prepared early by contacting childcare } \\
\text { services while the mother was still pregnant (No. 19) }\end{array}$ \\
\hline \multicolumn{2}{|r|}{ Adjusted mapping from failure } \\
\hline Target & A mother with borderline personality disorder \\
\hline
\end{tabular}


Continued

\begin{tabular}{|c|c|}
\hline Base & $\begin{array}{l}\text { A failure of being made to act like a messenger } \\
\text { by a client with borderline personality disorder }\end{array}$ \\
\hline Mapping & $\begin{array}{l}\text { Tell in advance what can or cannot be done for the } \\
\text { mother to prevent being asked to do what PHNs cannot do }\end{array}$ \\
\hline $\begin{array}{l}\text { Story } \\
\text { interviewed }\end{array}$ & $\begin{array}{l}\text { [...] The mother suffered from borderline personality disorder. } \\
\text { So, I told her in advance what I can or cannot do. In the mental health } \\
\text { department, a client asked me to do all the paperwork submitted to the } \\
\text { office while I was home visiting, so I acted like a messenger. } \\
\text { It was a failure. So I tried to not be relied on as much (No. 53) }\end{array}$ \\
\hline & Attitude mapping when supporting \\
\hline Target & A mother whose husband killed himself the day after the birth \\
\hline Base & Attitude towards managing consultations about suicide or suicidal ideation \\
\hline Mapping & $\begin{array}{l}\text { Being attitude of mind for managing consultation } \\
\text { with the mother whose husband killed himself }\end{array}$ \\
\hline $\begin{array}{l}\text { Story } \\
\text { interviewed }\end{array}$ & $\begin{array}{l}\text { I heard in my maternity hospital about a mother whose husband killed } \\
\text { himself the day after the birth and required support to prevent her from } \\
\text { committing joint suicide with the baby. In the maternal health department, } \\
\text { other PHNs did not know how to support her and felt timid to try } \\
\text { because of the difficulty in performing consultation. This was the } \\
\text { first time such a mother came to the maternal health department. } \\
\text { In the mental health department, I prepared for consultations about } \\
\text { suicide or suicidal ideation because it was the final department where } \\
\text { difficult consultations were delivered from other departments (No. 23) }\end{array}$ \\
\hline
\end{tabular}

successful by PHNs, thereby confirming their PSS for that situation. However, PHNs judged five PSS as failures or as difficult to accurately judge. This led them to reconsider how they used and/or should use analogy for these five PSS and thereby gain a learning experience. An exemplar of a PSS evaluated as a failure was presented by one PHN:

A mother interrupted her treatment for schizophrenia and said to me that she was "cured." Based on my experiences with other patients, I believed that the condition of such patients becomes worse without treatment. I tried to make her restart treatment. However, a psychiatrist recommended supporting the mother's current condition because the psychiatrist thought that the mother suffered from borderline personality disorder, not schizophrenia. I regret that I reacted too strongly to a past diagnosis (No. 24).

\section{Discussion}

We posed two research questions: how do PHNs apply past PSS to new areas of practices (i.e., can mental health PSS be applied to maternal health PSS), and can PSS be developed using the PSS learned in past areas (i.e., can maternal health PSS be developed using mental health PSS)?

\subsection{Applying Past PSS to New Areas of Practice}

All eight PHNs applied mental health PSS to maternal health PSS. We identified some characteristics regarding how to apply the PSS by analogy stage.

In the selection stage, PHNs were likely to select a base according to structural 
similarity, which included client reactions, client condition or situation, and methods of support by PHNs, even if surface similarity was available. This result is supported by previous findings [15] that surface similarity is most important for determining base retrieval, but in real-world conditions, structural similarity is used more frequently. This is perhaps because PHNs often do home visits and face-to-face interviews that then become training for them in assessing clients in the clients' daily living environments.

In the mapping stage, few PSS demonstrated mapping with high-level abstraction. According to analogy research, mapping with high levels of abstraction in similarity is absolutely necessary and provides analogies with a wider range of applications [21]. In general, nurses who tend to use knowledge in more abstract ways tend to make decisions that are more creative and diverse [24]. Some attempted mapping as a trial when they were unable to find solutions to the current problem. PHNs who had not worked in maternal health departments previously were more likely to use high-level mapping, perhaps because they had fewer solutions for problems in the new department, and thus required higherlevel analogies. This interpretation is supported by the finding that analogy tends to work better in uncertain situations [6]. Furthermore, consultations in this study were mainly aimed at preventing child abuse. In such serious situations, using high-level analogies as trials may be inappropriate; however, because analogy also tends to be guided by a person's goals [12], in a situation wherein, a child's life may be threatened, PHNs will doubtlessly be more motivated to achieve their goal. Thus, more secure PSS (i.e., those more likely to succeed) may be provided by adjusting mental health PSS. For these reasons, PHNs do not always require high-level analogy; their use of such analogy depends on the seriousness of the problem. In sum, low-level abstractions may be appropriate for some serious problems, while high-level abstractions may be appropriate for less serious problems or problems without solutions.

Preventive mapping (or preventive analogy, hereafter) was found to be a signature analogy for PHNs. Preventive analogy is PHNs' inferring a future change in a patient's condition from their background situation and conditions, with the goal of preventing a worsening of the current situation. For instance, PHNs' motivation in a child endangerment situation is in response to the ethical implications of that situation; in other words, PHNs might act to avoid negative consequences such as joint suicide or child neglect. Preventive perspectives are important for PHNs' goals and activities and are included in key characteristic of practice of public health nursing [25] and the activities guidelines for Japanese PHNs [26]. While the finding that PHNs used preventive analogy is unsurprising, it was meaningful to confirm in a research capacity because it is important for PHNs and for educated novice students to acquire these skills during their nursing education.

\subsection{Developing PSS Using the PSS Learned in Other Areas}

Two findings supported that PSS can be developed using PSS learned in other areas. The first aspect concerned one of the signature analogies for PHNs, "analo- 
gy developed from failures and successes". Many PSS of adjusted mapping from failure overlapped with preventive mapping, likely because PHNs learned from the failure of a mental health PSS and therefore adjusted the maternal health PSS accordingly in current new area, and used this adjusted PSS preventively in future cases. PHNs also reconsidered all maternal health PSS that they judged as unsuccessful. This might lead them to adjust this unsuccessful PSS and try it again in the future. PHNs' process of using, reflecting on, learning from their skills, and then testing new skills is reminiscent of experiential learning theory [27]. PHNs developed their skills via continuous revision of analogies in practice. Professional development cannot be truly completed, and professional skill goes beyond current highest skill [28]. PHNs can develop their own skills beyond their current levels through learning from failures and successes. We proposed that this set of skills can be practiced and taught in continuing clinical education possibly through the use of case examples and PBL.

The second finding pertains to PHNs who had worked in maternal health departments before working in mental health departments. PHNs that had experience in a maternal health department also used analogies based on mental health PSS rather than falling back on their previously used maternal health PSS. In other words, existing maternal health PSS were improved using analogies of mental health PSS. Although PHNs had transferred to a department requiring specific skills, they could develop these skills through analogy.

\subsection{Implications for Nursing Education}

The findings in this study on PSS using analogy may contribute to the improvement of nursing education strategies including PBL to facilitate PSS and related critical thinking skills. We found that nurses have characteristics in applying PSS that may differ from those of other professionals. If such nurse-specific characteristics reflect what nurses learn from nursing educational programs, these programs may become more effective and practical. For instance, the finding that PHNs were more likely to select a base according to structural similarity such as clients' reactions rather than surface similarity such as psychiatric symptoms, may be an important point in education. Problem examples in educational programs could include clients' reactions and situations, as it would help nurses acquire more careful observation skills, which are necessary to identify structural similarity.

Nursing students should be taught the skills for using analogy effectively. One important finding - namely, that PHNs tend to apply PSS with a low level of abstraction as a secure strategy in serious situations such as child abuse-shows the necessity of varying the abstraction of analogy depending on the situation. In other words, nursing students should learn how to use analogy differently and effectively depending on the severity of the problem. Preventive analogies are also essential PSS, especially for nurses working in public health fields. Nursing students could learn signature PSS by incorporating these skills into PBL scenarios. Current PBL scenarios used in nursing education usually include only spe- 
cific problematic situations, wherein students identify target problems and, using their own initiative, demonstrate appropriate solutions. PBL using analogy would be more helpful to students because it would provide PSS learned in other areas of practice by the PHN to help solve problematic current situations. Furthermore, as shown in Table 2, serious situations could be prevented from escalating to critical situations by use of analogy-specifically, PSS can be retrieved according to structural similarities.

In terms of continuing education, sharing domain-specific PSS among nurses is important for overall skill development. Specifically, nurses can learn from the consultations and information of other nurses and apply these skills to their own consultations using analogy. Next, this study showed that transferring departments does not mean an interruption in skill development of nurses. If nurses who transfer departments understand this, they may become motivated to work harder, even if considerable time and effort are needed. Moreover, if nurses know their PSS can be applicable to their nursing in other departments, they may be more interested in making departmental moves, and anticipate and look for ways to use their knowledge and skill sets in new settings. Therefore, transferring departments for nurses could be viewed as a positive strategy for developing PSS and important to their career development.

Among medical doctors, computer-aided decision support systems have become popular in clinical settings [29]. One such system-fuzzy cognitive mapscan be used to help address the specific problems of mapping knowledge bases for medical diagnoses [30], and is similar to PSS using analogy in the current study. Therefore, similar computer-aided support systems can be developed for use in public health nursing in the future. Given that our findings represent knowledge accumulated from experts, it is expected that they will be useful in the development of such systems.

\subsection{Limitations and Future Research}

This study had some limitations. First, because we used case studies, which aim to expand and generalize theories, we cannot generalize our results statistically. A quantitative study on this topic could overcome this limitation. Second, our results are limited to the domains of mental health and maternal health. Finally, we focused only on PSS in consultation, while PHNs use many different skills in practice. How analogy affects PHNs' other skills must be studied in the future. Furthermore, more research regarding PSS using analogy is needed in other nursing departments in order to clarify the signature PSS for nurses that may contribute to the development of more effective nursing education programs.

\section{Conclusion}

Through a multiple case study on PSS using analogy, we clarified how PHNs applied past PSS to new areas of practice and how PSS could be developed using the PSS learned in these other areas. Specifically, they tended to select past PSS based on structural similarity and apply past PSS using a low level of abstraction of anal- 
ogy during serious situations. Furthermore, they applied PSS preventively to avoid worsening the current situation. We found that PHNs developed PSS from failures and successes and by using analogy itself.

\section{Acknowledgements}

We would like to thank the research participants. This work was supported by research grant from the Mitsubishi Foundation, 2013 (Program Grant Number 25313).

\section{Conflicts of Interest}

The authors have no conflicting interest to declare.

\section{Authors' Contributions}

M. K. carried out the data collection and participated in study design, analysis, and manuscript preparation. T. S., A. T., S. N., and K. M. participated in study analysis and manuscript preparation. All authors read and approved the final manuscript.

\section{References}

[1] Sangestani, G. and Khatiban, M. (2013) Comparison of Problem-Based Learning and Lecture-Based Learning in Midwifery. Nurse Education Today, 33, 791-795. https://doi.org/10.1016/j.nedt.2012.03.010

[2] Choi, E., Lindquist, R. and Song, Y. (2014) Effects of Problem-Based Learning vs. Traditional Lecture on Korean Nursing Students' Critical Thinking, Problem-Solving, and Self-Directed Learning. Nurse Education Today, 34, 52-56. https://doi.org/10.1016/j.nedt.2013.02.012

[3] Tanner, C. (2006) Thinking Like a Nurse: A Research-Based Model of Clinical Judgment in Nursing. Journal of Nursing Education, 45, 204-211.

[4] Shin, I.S. and Kim, J.H. (2013) The Effect of Problem-Based Learning in Nursing Education: A Meta-Analysis. Advances in Health Sciences Education, 18, 1103 1120. https://doi.org/10.1007/s10459-012-9436-2

[5] Worrell, J.A. and Profetto-McGrath, J. (2007) Critical Thinking as an Outcome of Context-Based Learning among Post RN Students: A Literature Review. Nurse Education Today, 27, 420-426. https://doi.org/10.1016/j.nedt.2006.07.004

[6] Chan, J., Paletz, S.B.F. and Schunn, C.D. (2012) Analogy as a Strategy for Supporting Complex Problem Solving under Uncertainty. Memory \& Cognition, 40, 1352 1365. https://doi.org/10.3758/s13421-012-0227-z

[7] Kusumi, T. and Matsubara, H. (1993) Ninchishinrigaku ni okeru anaroji kenkyu [Cognitive Perspectives on the Problems of Analogy]. IPSJ Magazine, 34, 536-546.

[8] Reeves, L. and Weisberg, R.W. (1994) The Role of Content and Abstract Information in Analogical Transfer. Psychological Bulletin, 115, 381-400.

https://doi.org/10.1037/0033-2909.115.3.381

[9] Dumas, D., Alexander, P.A. and Grossnickle, E.M. (2013) Relational Reasoning and Its Manifestations in the Educational Context: A Systematic Review of the Literature. Educational Psychology Review, 25, 391-427. https://doi.org/10.1007/s10648-013-9224-4

[10] Huntsman, L. (2008) Parents with Mental Health Issues: Consequences for Children and Effectiveness of Interventions Designed to Assist Children and Their Families. 
Centre for Parenting \& Research, Service System Development Division and NSW Department of Community Services, Ashfield.

[11] Japanese Nursing Association (2015) Hokenshino katsudokiso nikansuru kisochosa hokokusho [Basic Survey Report about Activities of Public Health Nurses]. Japanese Nursing Association, Tokyo.

[12] Holyoak, K. and Thagard, P. (1995) Mental Leaps Analogy in Creative Thought. MIT Press, Cambridge.

[13] Hano, Y. and Chihara, T. (1996) Anarogi katei ni okeru ninchi konponento [Cognitive Components in Analogical Reasoning Process]. The Faculty of Education Shiga University, 46, 203-220.

[14] Holyoak, K. and Koh, K. (1987) Surface and Structural Similarity in Analogical Transfer. Memory \& Cognition, 15, 332-340. https://doi.org/10.3758/BF03197035

[15] Blanchette, I. and Dunbar, K. (2000) How Analogies Are Generated: The Roles of Structural and Superficial Similarity. Memory \& Cognition., 28, 108-124. https://doi.org/10.3758/BF03211580

[16] Gentner, D., Rattermann, M.J. and Forbus, K.D. (1993) The Roles of Similarity in Transfer: Separating Retrievability from Inferential Soundness. Cognitive Psychology, 25, 524-575. https://doi.org/10.1006/cogp.1993.1013

[17] Gentner, D. and Markman, A.B. (1997) Structure Mapping in Analogy and Similarity. American Psychologist, 52, 45-56. https://doi.org/10.1037/0003-066X.52.1.45

[18] Nikata, K. and Shimada, H. (2005) Ruidai sakusei keiken ga ruisuiteki mondai kaiketsu ni ataeru koka [Facilitation of Analogical Transfer by Posing an Analogous Problem for Oneself]. Japanese Journal of Educational Psychology, 53, 381-392. https://doi.org/10.5926/jjep1953.53.3_381

[19] Sakurai, S., Wakizono, R. and Harao, M. (1993) Chusyoka ni motoduku ruisui [Abstraction Base Analogy]. IPSJ Magzine, 34, 558-565.

[20] Yin, R.K. (2013) Case Study Research: Design and Methods. 5th Edition, Sage Publications, California.

[21] Holland, J.H., Holyoak, K.J., Nisbett, R.E. and Thagard, P.R. (1986) Indaksyon: Suiron gakusyu hakken no togo riron ni mukete [Induction: Processes of Inference, Learning, and Discovery]. MIT Press, Cambridge.

[22] Minnesota Department of Health, Division of Community Health Services and Public Health Nursing Section (2001) Public Health Interventions: Applications for Public Health Nursing Practice.

[23] Hosoya, I. (2011) Anaroji shiko [Analogical Thinking]. Toyo Keizai Inc., Tokyo.

[24] Tanner, C.A. (2006) Thinking Like a Nurse: A Research-Based Model of Clinical Judgment in Nursing. Journal of Nursing Education, 45, 204-211.

[25] American Public Health Association Public Health Nursing Section (2013) The Definition and Practice of Public Health Nursing: A Statement of the Public Health Nursing Section. American Public Health Association, Washington DC.

[26] Health Service Bureau, Ministry of Health, Labour and Welfare (2013) Chiiki ni okeru hokenshi no hoken katsudo ni tsuite [Community Health Activities by Public Health Nurses]. L. and W. Health Service Bureau, Ministry of Health, Tokyo.

[27] Kolb, D.A. and Fry, R. (1975) Toward an Applied Theory of Experiential Learning. In: Cooper, C., Ed., Theories of Group Process, John Wiley, London, 33-57.

[28] Dall'Alba, G. and Sandberg, J. (2006) Unveiling Professional Development: A Critical Review of Stage Models. Review of Educational Research, 76, 383-412. https://doi.org/10.3102/00346543076003383 
[29] Belle, A., Kon Mark, A. and Najarian, K. (2013) Biomedical Informatics for Computer-Aided Decision Support Systems: A Survey. Scientific World Journal, 2013, Article ID: 769639. https://doi.org/10.1155/2013/769639

[30] Innocent, P.R. and John, R.I. (2004) Computer Aided Fuzzy Medical Diagnosis. Information Science, 162, 81-104. https://doi.org/10.1016/j.ins.2004.03.003

Submit or recommend next manuscript to SCIRP and we will provide best service for you:

Accepting pre-submission inquiries through Email, Facebook, LinkedIn, Twitter, etc. A wide selection of journals (inclusive of 9 subjects, more than 200 journals)

Providing 24-hour high-quality service

User-friendly online submission system

Fair and swift peer-review system

Efficient typesetting and proofreading procedure

Display of the result of downloads and visits, as well as the number of cited articles

Maximum dissemination of your research work

Submit your manuscript at: http://papersubmission.scirp.org/

Or contact ojn@scirp.org 